\title{
Seeking Habitable Environments in Our Solar System: Curiosity on Mars*
}

\author{
Laurie Leshin $^{1}$ and the Mars Science Laboratory Science Team
}

\begin{abstract}
Exploring space is one of humankind's great endeavors, leading to technological innovation and discoveries that have the potential to answer the most fundamental human questions such as: Are We Alone in the Universe? NASA's Mars Curiosity Rover landed on Mars in 2012. With its highly advanced suite of cameras and sensors, Mars Curiosity has revealed an ancient Mars that billions of years ago would have been a hospitable habitat for simple life. Although we haven't yet discovered that life previously existed on Mars, Curiosity continues to provide a window into our neighboring planet's history that motivates expanded exploration by future robotic spacecraft as well as eventual crewed missions.
\end{abstract}

Keywords: Mars, Curiosity Rover, Astrobiology.

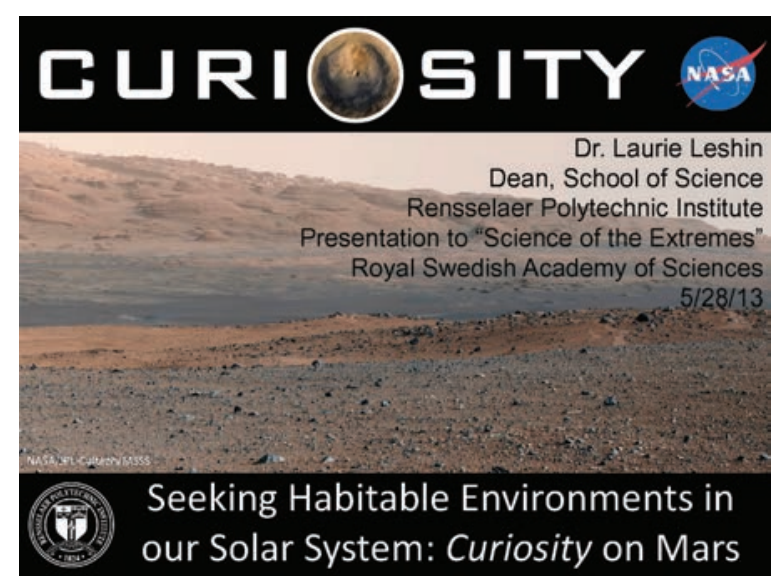

Laurie Leshin: Good morning, everybody. Thank you for having me. Thank you so much for the invitation. I'm thrilled to be here to share with you a little bit about an extreme environment that we're exploring right now with, here she is, our girl on Mars, yeah. So as Lorie said I come to you today from RPI, Rensselaer Polytechnic Institute. For those of you that may not have heard of it, it's actually was the first technological university in America. So we'll celebrate our $200^{\text {th }}$ birthday in 11 years. It's a wonderful science and technology university there, so fantastic.

So what I thought I would do today since we do have such exciting data that is literally coming down - I had 26 e-mails when I woke up this morning about our very latest data coming down from Mars. Just to share with you a bit about what we're trying to do with the Curiosity rover and how that fits into a broader picture of trying to understand whether life is out there within our own solar system. And I think you'll hear different perspectives throughout the symposium on life in the universe, on life on earth and so I thought l'd focus on Mars today.

\footnotetext{
${ }^{1}$ Affiliation in 2013: School of Science, Rensselaer Polytechnic Institute, Troy NY, USA; Current Affiliation: Office of the President, Worcester Polytechnic Institute, Worcester, MA 01609, USA. Published online 16 May 2017; doi:10.1142/S252973251740003X

*This article was transcribed from a presentation delivered by Professor Laurie Leshin and the Mars Science Laboratory Science Team at the Molecular Frontiers Symposium, Royal Swedish Academy of Sciences, May 2013. It is published here in MFJ with permission from Professor Laurie Leshin and the Mars Science Laboratory Science Team.

This is an Open Access article published by World Scientific Publishing Company. It is distributed under the terms of the Creative Commons Attribution 4.0 (CC-BY) License. Further distribution of this work is permitted, provided the original work is properly cited.
} 


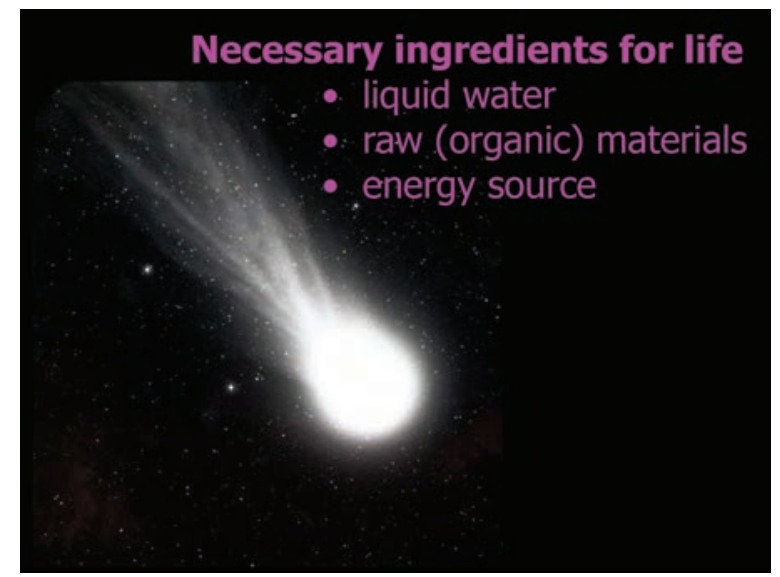

I'm just going to say a bit at the beginning and this is highly simplified, but the general thinking about when we think about where to explore for life, we think about places that might have had the ingredients that could have led to life. And from studying life on earth and its history, which you'll hear about more in the symposium and which is a fascinating subject, but we see over and over again the things that are the raw ingredients that could lead to life. We think we need liquid water to have that medium to do the biochemistry that it takes for living cells and living organisms to prosper, we need the raw chemicals, carbons, hydrogens, phosphorus, nitrogen, those things that make up living things. And then you need an energy source. So stuff has to eat, right? Could be sunlight, could be other kinds of energy, plenty of microbes on earth eat rocks. So there's lots of good energy sources out there. So these are the different ingredients in our understanding of, say for example, the different energy sources for life has changed dramatically over the past few decades.

This is now sort of a very broad canvas on which to search for a life but when you ask yourself in our solar system, where are the places where we might think about going and looking for these ingredients in an environment where life could have gotten started? And then the question becomes If you find the ingredients, did you make the soup? And that's the big question. When we ask ourselves where in our solar system we would go to look for this environment, there are many possible targets including some in the outer solar system, places we wouldn't have imagined again a couple of decades ago, but thanks to missions like Voyager, we learned about the moons of Jupiter and now with Cassini about some of the moons of Saturn that may have habitable environments. But the one that we always come back to is this - Mars, my favorite planet outside of earth of course.

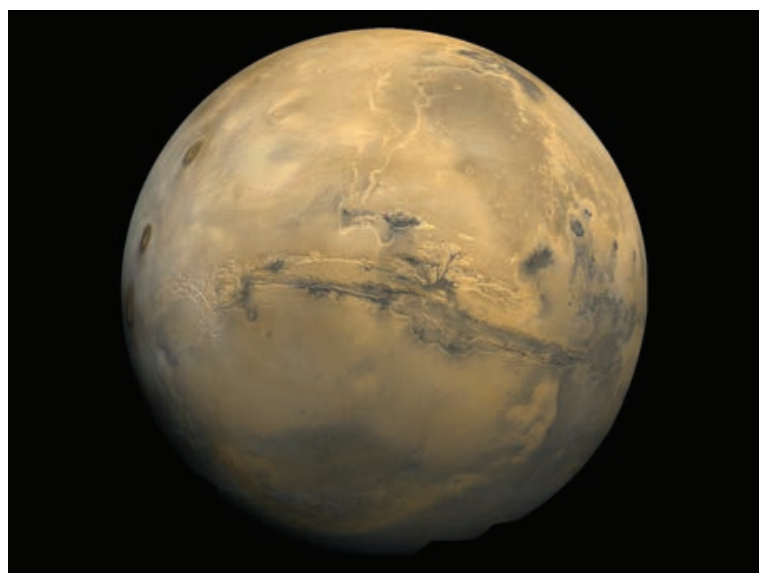

Mars is a fascinating place and has lots of features that geologists like me really love. It has giant volcanoes and huge canyon systems. This canyon system is, you know, the Grand Canyon in the US would be just a tiny little side canyon. Here this is actually the length of the entire United States, sorry for the US reference but those are the audiences I usually speak to. Mars has polar caps. Its axis is tilted so it has seasons, winters and summers. And the polar caps wax and wane in those seasons. It has a day that's just a little bit longer than an earth day about 24 hours and 39 minutes. So there are many things on Mars that kind of feel familiar to us, things that we can relate to. But the things that make it the most interesting from an astrobiology perspective, that is the perspective of looking for life beyond earth, have to do with features like this one which is a little bit hard to see here, but nonetheless is a feature formed by water. And I'll show you some more pictures that have such features on Mars and tell you a bit about where we're exploring there and why.

We know that today, it's quite cold at the martian surface. The temperature during the day hovers around the freezing mark and the atmosphere is very thin, it does have an atmosphere mostly carbon dioxide but it's only about $1 \%$ the thickness of the earth's atmosphere. So liquid water today is not something that's stable long term that it would either freeze or evaporate very quickly. But yet we see thousands and thousands of dried up river beds on the surface of Mars. And so we think that there was a time in the past, probably around the same time that life was emerging on earth, where Mars did have abundant liquid water. And we know that from things like comets, as I showed in that last picture, that they're always going to be organic materials raining down on the surface, if not being formed locally. And of course with things like volcanoes, there's plenty of energy sources. So there are your ingredients and so the question is again, did we make the soup?

So Mars has been an object of our fascination for studies of life. And we have sent to Mars a fantastic machine to help us explore and understand whether or not life could have gotten started there. Now how many people watched 
the landing of Curiosity, at least it was mostly, was it during the day here! Yes in the morning here, right? All right, very good.

So we landed on Mars successfully on August $5^{\text {th }}$, California time, that's my birthday. So it was a very, very good birthday. So just to take you back there for a moment let's watch a little video at: https://mars.nasa.gov./multimedia/ videos

So this landing system, we go from 13,000 miles an hour to 0 in 7 minutes.

From entering the top of the atmosphere here, that's an animation.

The rover itself is folded inside this capsule. I don't think he cut his hair for the whole 10 years we worked on the machine.

So we just got these little tones from the rover saying, okay, now, l've started to slow down, now l've deployed my parachute, things like that. But we could do nothing about it at all. It actually it happened 8 minutes earlier because Mars is that far away from us. So slowing down and steering in the atmosphere.

We are sending back data through an orbiter. That's the head of JPL. That's the head of NASA. Supersonic parachute. An actual picture in the orbiter, showed us going through the atmosphere we didn't get that till later.

All right, this next part is the part that still scares the heck out of me. We just dropped the rover. We're coming down on rockets because the atmosphere isn't thick enough to slow us down enough on a parachute. And then if that weren't enough, we lowered the rover down on a tether, dropped the wheels. Touch down, cut the tethers, and...

Woo-hoo! Nerds celebrating, yay, it was quite a moment. Most of these guys have worked on this machine for about 8 years including me.

And within 2 minutes or so of landing we had the first images down.

And here we are on Mars.

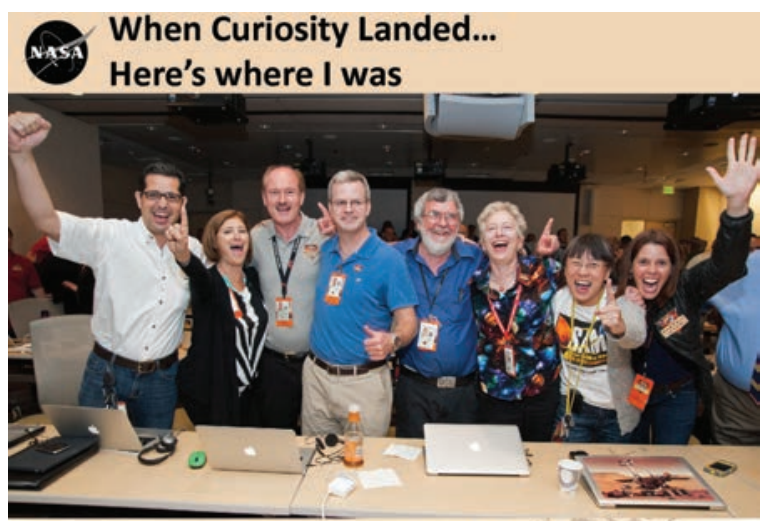

And Curiosity was...

So this landing system was quite something and really l'Il tell you a bit about how it enabled so much the scientific exploration that we're now doing with Curiosity. So you saw in the video mission control, where all of the engineers were. And here's where scientists were. We didn't get the blue shirts but we were all together, also at the Jet Propulsion Lab in California. This was again about 2 minutes after we landed. And again, for those of us who've worked on this mission for almost a decade, it was a pretty exciting moment especially after such a harrowing landing.

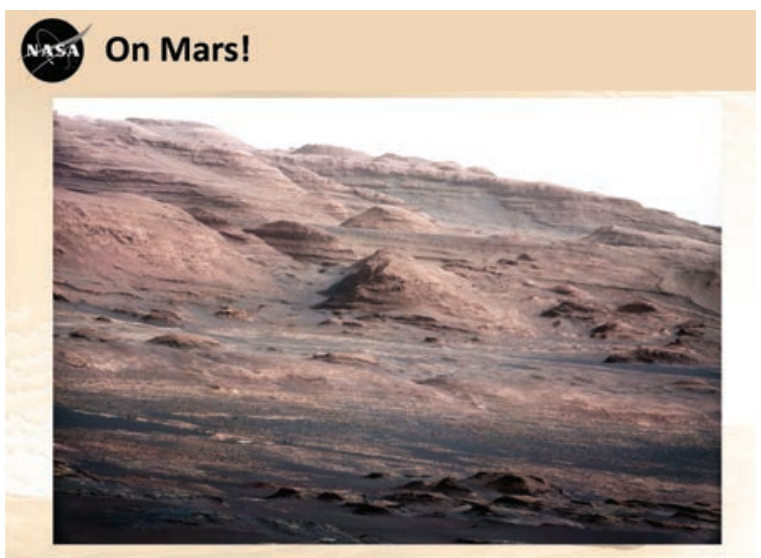

And here's where Curiosity was - on Mars sitting at the base of a gorgeous mountain, but I'm getting a little bit ahead of myself here because that was not actually what the first picture looked like. The first picture looked like the one on the left. 
The actual first picture looked like this...

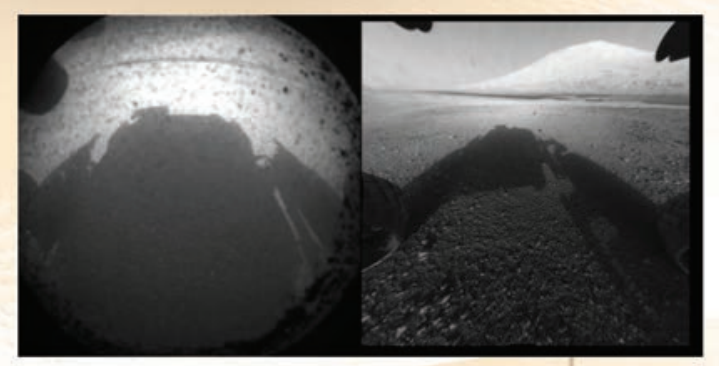

But I'm getting ahead of myself...

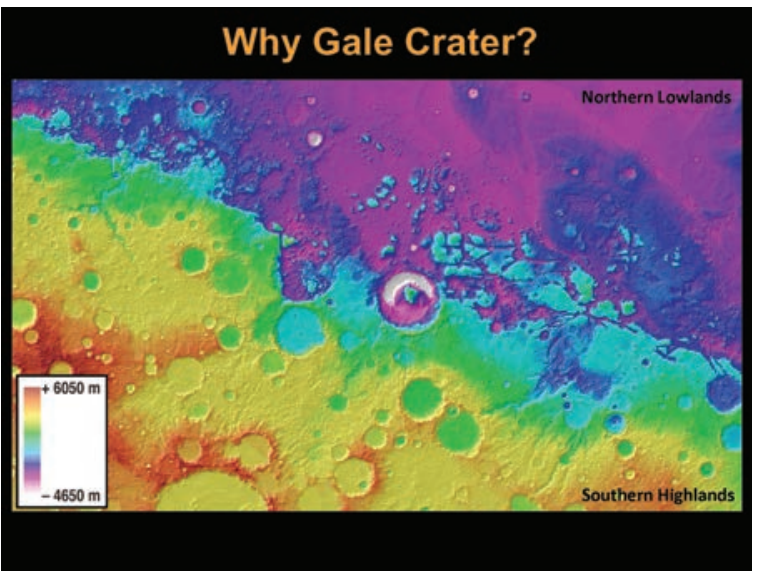

So let's talk about where we chose to go on Mars. If you want to go explore for life on Mars you want to go to places where you have the best opportunity to find those ingredients of life, specifically look for water which again we think has been on Mars in the past, and we want to go to a place where water likely would have stuck around for a while. So this is actually the place that we landed. This is a crater called Gale. It's about $150 \mathrm{~km}$ across. And this is a different kind of picture of Mars you're looking at now. This is looking at different altitudes. So
I call it a picture only a mother could love. And that's because it was actually taken through a lens cap. The cameras had transparent lens caps on them and those rockets that we came down on kicked up quite a lot of dirt and so they're very dirty. But here you can see that we could tell the rover was healthy, you can see there's the shadow. And I remember at the time that night people said, okay, so these are these sand dunes and this is the mountain right here. And I was looking at that and going, are you crazy? That's not the mountain. Well, sure enough the next day when we opened the lens cap on the camera, and in the image on the right, there's the mountain that we landed right next to, and you'll see these dunes in another picture l'm about to show you, this dark line here are some sand dunes that were that were near here - but again I'm getting ahead of myself.

red is very high and purple is very low. And you can see this crater, it sits at a very interesting place. This very interesting geologic boundary on Mars that actually goes around the whole planet. The southern parts of Mars are very high and cratered. You can see lots of craters. The northern parts of Mars tend to be much lower and much smoother.

And here's this crater right on the boundary. And some very interesting things about this crater, first that it sits on the boundary, and second that it has this big mountain in the middle. It's big peak that sticks up even higher than the edge of the crater which is very interesting. I'll show you more about that. And third is that it does have this very low spot here. So white is way down here, the lowest of the low. So in this whole region kind of the lowest of the low is here in the floor of this crater. But the most interesting stuff and probably the easiest ones to see are over here. Can you see these nice dried river channels? And there's one right here that breaches the edge of Gale crater. And so it's quite clear that water flowed into this crater at some point and of course water flows downhill. If you want to go to the place where the water might have pooled, the bottom of this crater is a pretty good place. So these were all things that made us very interested in visiting Gale. 

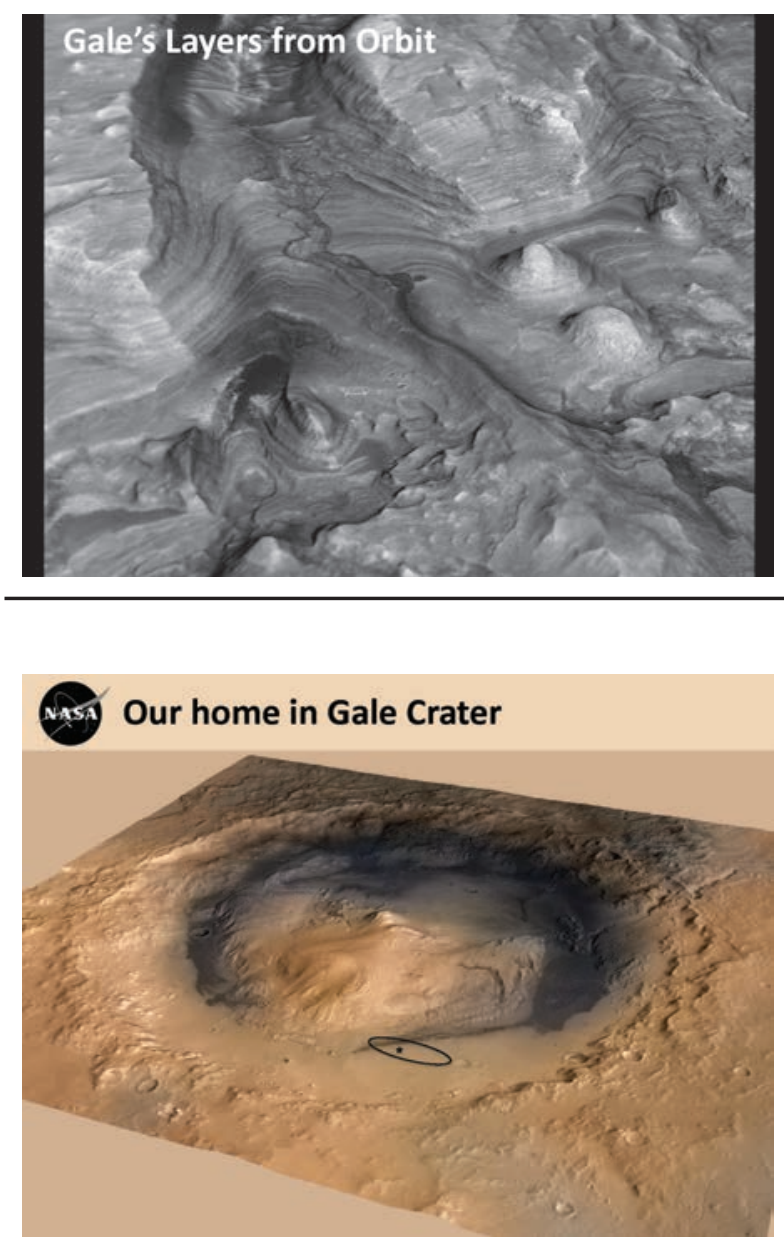

And in addition, when we look from orbit we could see layers in the mountain. This is now a picture from one of our scientific orbiters going around Mars. And we saw layers, layers, layers. To a geologist, these layers are like candy. This is how we read the historical record of a planet, is in these layers. So it looked like a very interesting place to go. And we chose that as our landing site after looking at hundreds and hundreds of sites and scientists fighting it out about which was the best place to go.

Here's now another view of our home in Gale crater. There is the crater, this is the mountain, here's those dark dunes that I just told you about. And what we said to the engineers, we scientists said okay we want to go HERE, we want you to snuggle us up right next to this big MOUNTAIN and so we can drive this rover up the mountain. We understand you probably can't land right on the mountain but just get us as close as you possibly can to the mountain. And they said, are you crazy, you're going to make us land between this terrible rim of this crater and this humungous mountain? Well, they said okay, okay so we'll have to build you this kind of crazy landing system to get you down there. We can't guarantee you can land in any one spot but we can say with $99 \%$ certainty, you could land within this ellipse. And that's $20 \mathrm{~km}$ in size, the size of that ellipse. And we actually landed right here where the star is. So they did a very good job getting us where we wanted to be.

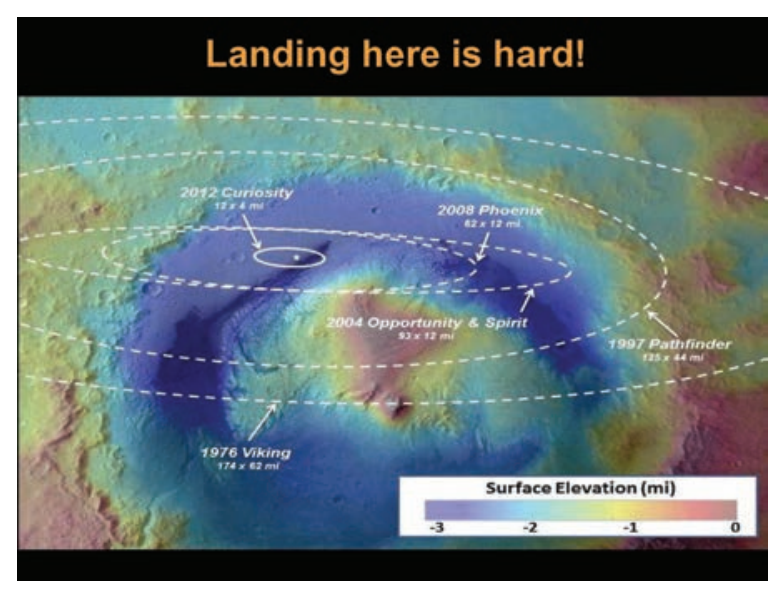

And it turns out that this is a very hard thing to do. If we compare this, so here's our crater again I flipped it around, there is the mountain, this is our ellipse, there's the edge of the crater. If we had tried to do this with, say Spirit and Opportunity, those cute little rovers that have been driving around Mars for 9 years, that's how big their ellipse was or back for Viking, again $99 \%$ probability that's how big that was. We never would have been able to go to this landing site ever before. And so I think this is one of the big innovations of Curiosity. It's a combination of scientific innovation with engineering innovation that got us here. And they did it by steering through the atmosphere - that's how they were able to shrink down the size of that landing ellipse. So good job on the engineers' part for getting us right up next to this mountain. And also to for building us an extraordinarily capable Rover. 


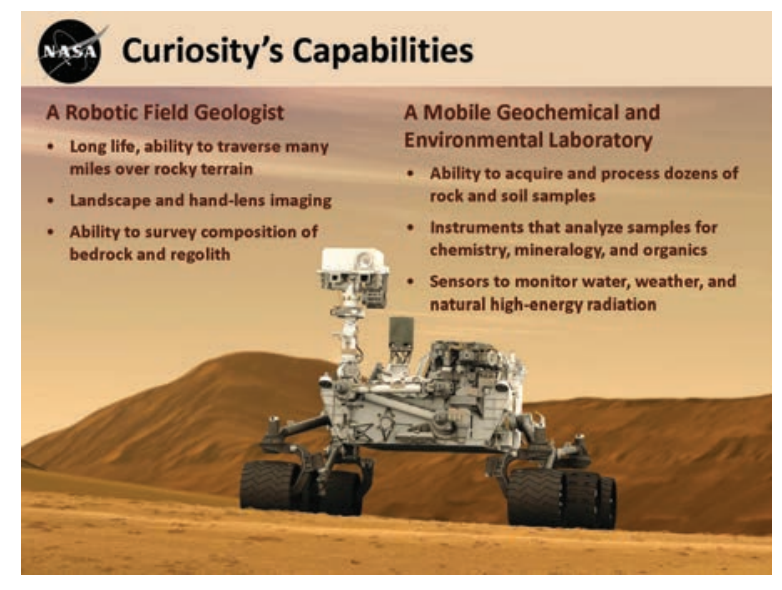

So if you said on earth I want to go and I want to explore a site for life or for any other geologic reason, what would you do? What I would do as a geologist is first, I would survey the site, I would look around, l'd look for the most interesting areas to go, then l'd walk up to those areas that looked the most interesting and start picking up rocks, next l'd pull out of my pocket my hand lens, my little magnifying glass that every geologist carries in their pocket in the field, and l'd look at that rock very close up and try to do a quick determination of what kind of rock it was. Is it an igneous rock or a sedimentary rock, for example. And finally if it was a very interesting rock, l'd throw it in my backpack and l'd bring it back to my lab to analyze the chemical composition in great detail. Well, that's basically what Curiosity does on Mars - everything except the backpack because it can't come back to earth. So we put the lab here in Curiosity's belly, she's got a couple of very high-end analytical instruments in there that she's carried with her to Mars. I think the rover is a girl by the way, it's like a ship, right? So I think she's a girl.

So, she is a robotic field geologist in that is she can traverse across lots of different types of terrains and drive right up to rocks. She can look at them with her magnifying glass. She's got a great camera on the end of her arm here that does good microscopic imaging. And she can do quick surveys of the kinds of rocks things are again to look for things that might be different or interesting. And then she can scoop or drill dirt or rocks and put those samples into these incredible analytical labs here inside the belly of the rover. She also has a good weather station and she's looking at radiation which l'll talk about a little later that can help us understand how easy or difficult it will be for humans eventually to explore Mars.

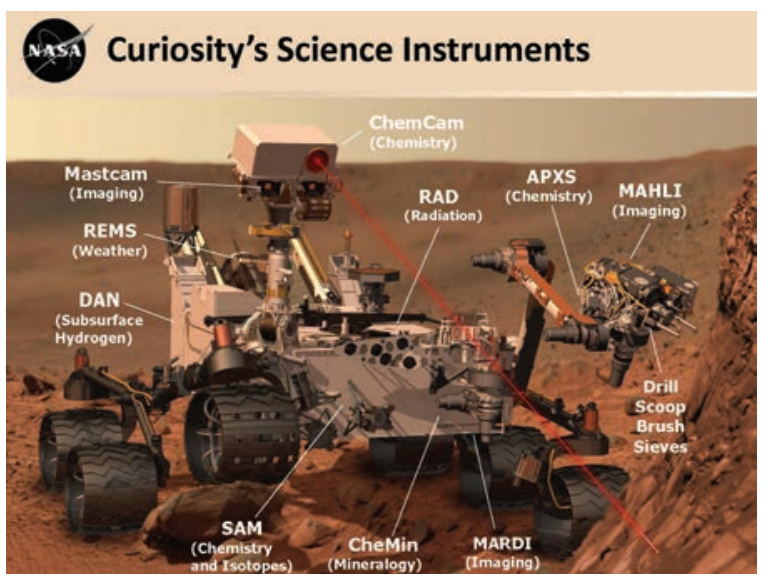

So that's an overview of her capabilities in general. She was basically built to do what I would do if I could go to Mars. I'd just be throwing up the whole time but she does doesn't do that. So that's good. So she's got 10 scientific instruments that's an incredibly capable system. The payload, the scientific instruments, weigh 10 times more than the payload we have on Spirit and Opportunity. So this is by far the most capable machine we've ever sent to the surface of another planet. Everything from very high resolution cameras, HD video, stereo and to the cameras on and of the robotic arm. This robotic arm is $2 \mathrm{~m}$ long, the mast is $2 \mathrm{~m}$ high. It's a very large rover. To an instrument that allows us to actually shoot a laser beam "pew, pew" at rocks and make a little puff of gas that we then look at with a emission spectroscopy. So it's different ways of analyzing the chemical composition of the rocks and minerals. She has scoops and drills and brushes and sieves that allow us to sample those materials in great detail. She has 17 different cameras (some for science, some for navigation). She is just incredibly well equipped.

Now let's dig in and talk a little bit about the results that we're finding that support the idea that Mars was once a habitable environment - recall that ultimately that's what Curiosity's goal is - to try to find habitable environments on Mars. If there was life there, could we detect it? Probably. We think that's going to be a hard thing, to find the exact right sample, but we think we should be able to find samples that will tell us whether or not Mars had a habitable environment. Look for those ingredients, if you will, and see them come together in a nice environment. So we landed on August $5^{\text {th }}$. We checked out the rover, we wiggled our wheels and made sure everything was working well. And then we hit the road. 


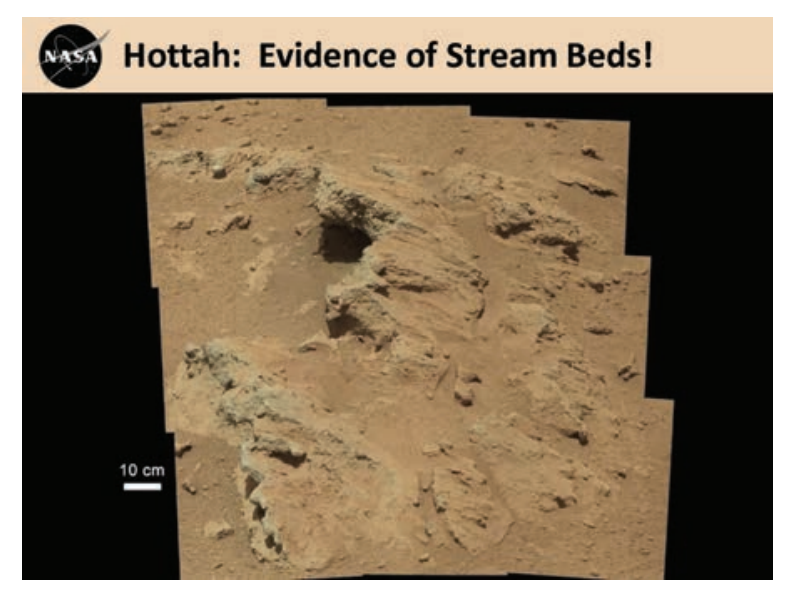

We started driving and within only a couple of weeks of being on the surface, we already started to find evidence that we were right about thinking that water had flown over the floor of the crater that we're sitting on. These are some of the first rocks that we came across as we were driving across the plain. They are kind of sticking up like somebody took a jackhammer to some sidewalk or something. And when you zoom in, l'm going to zoom in next on this little spot down here.

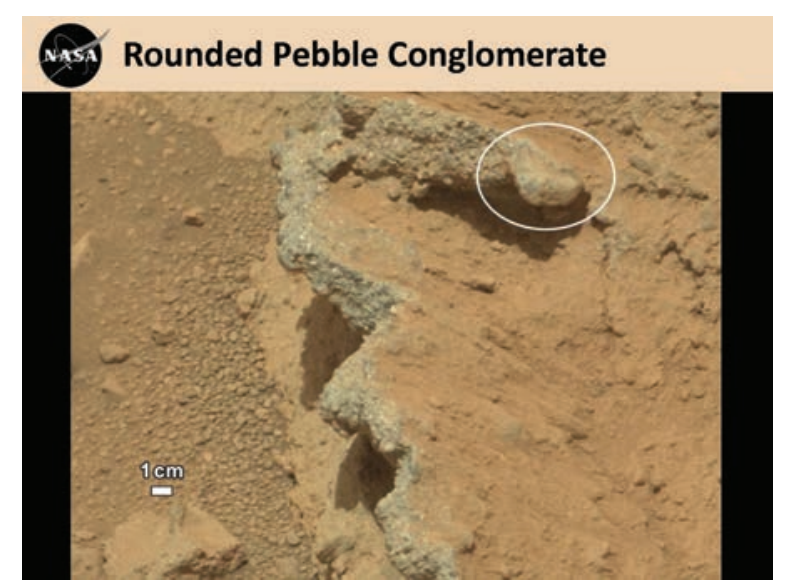

You can see nicely, I hope, that what this rock looks like is a very interesting kind of stone that looks like it's made up of other rocks stuck together and here's a nice big clasp that's very rounded. I like to actually look down here at the pile of stuff that's weathering out of this edge right here and there's lots of nice little rounded pebbles that have come out of this rock. So this is a rock that's made up of rounded other rocks that have been cemented together. On earth this would be a nice pebble conglomerate, that's what we call this kind of rock, and they form in streambeds. The pebbles were rounded by the flow of water. And so here, just right away, just from looking at the types of rocks that we're finding, we saw evidence early on that water did flow across the surface of the floor of this crater. At this point it was too early in the mission to use our chemical laboratory so we didn't actually get a drill into this rock or anything, but who knows perhaps if we drive back by it on our way to the mountain we will stop again and we'll see. So early on just seeing the right kind of rocks gave us positive indications about water.

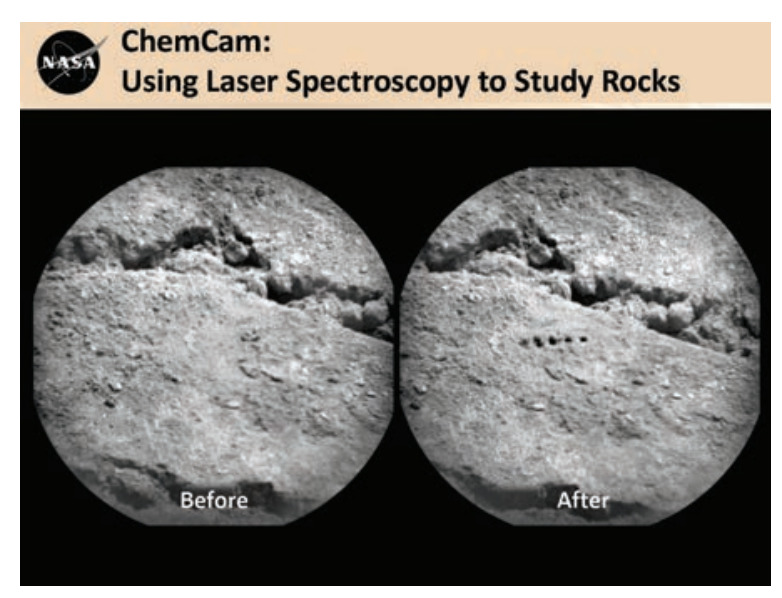

We were also starting to use the laser on our head to blast little holes in rocks. So just to give you a sense of this and each one of these holes is about half a millimeter in size, 500 microns. And they're done from a few meters away. And again they make this poof of gas and we get a nice spectrum for that. It's a great way to do a quick survey. So when you stop at a site and you can just blast the different rocks and see does one of them stand out as being different. So, but we're just making tiny little holes. 

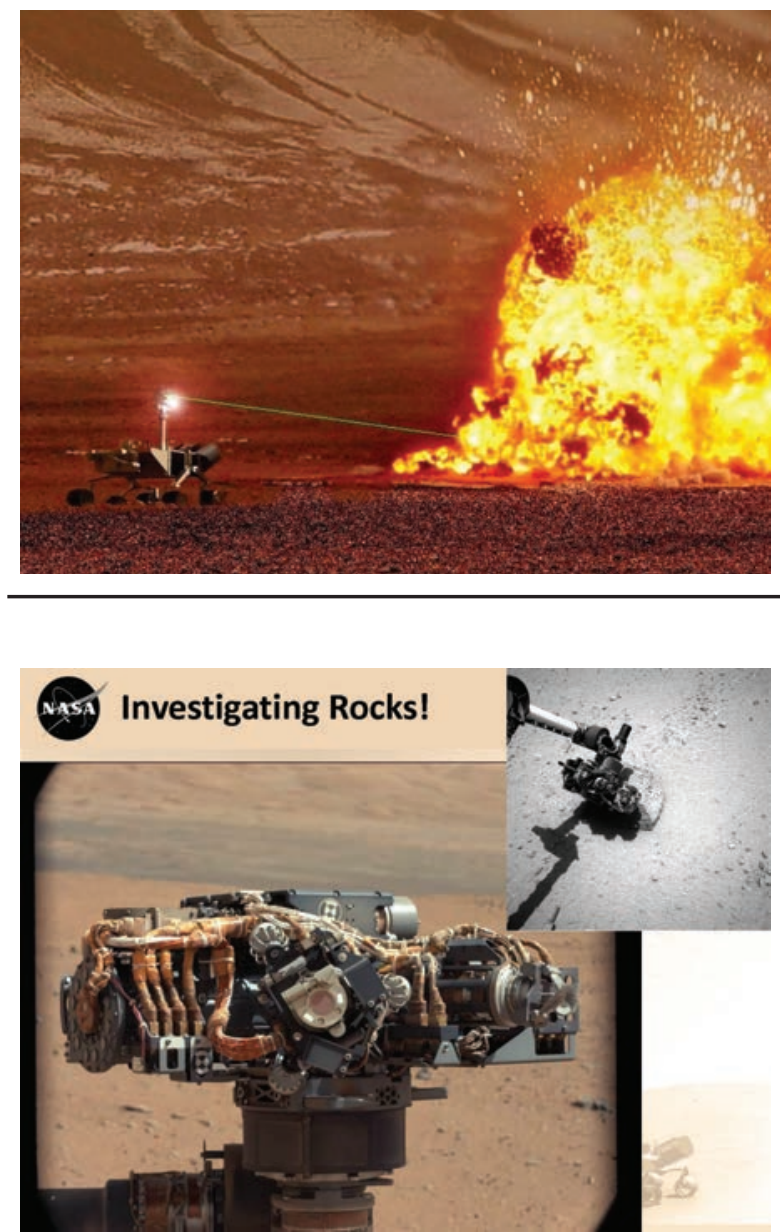

We have several different ways of investigating the samples of Mars chemically and so I'm sharing those with you today. In addition to our laser spectroscopy, we have an alpha particle X-ray spectrometer (APXS) on the end of our robotic arm. This is what the end of the robotic arm looks like. It weighs 200
This picture of an explosion is NOT what we're doing. People think that we must be blowing things up on Mars. That's not what we're doing, we're just making tiny little holes in the rocks, that's fascinating enough! pounds, it's amazing. It's very complicated! This is actually our hand lens, the thing that a geologist carries in their pocket to look at rocks close up, but on the other side of this turret is the APXS spectrometer and here it is deployed on a rock at the surface that basically bombards the rock with alpha particles and looks at backscattered X-rays that have a particular wavelength for different kinds of chemical elements so you can tell how much silicon, how much magnesium, how much aluminum etc. and you can determine the kinds of rocks you are looking at.

This rock is a nice basalt that we picked which is volcanic rock, for the first rock that we analyzed on Mars. It turns out this is a very interesting composition of basalt. I'm not going to talk about it but it has a lot of alkalis, potassium and sodium, very much like the rocks formed in ocean islands on the earth, but different than any we had previously found on Mars before. So it turned out that the first rock we analyzed with the APXS, which we specifically picked to be kind of a boring igneous rock, wasn't boring at all. So that's kind of fun and exciting.

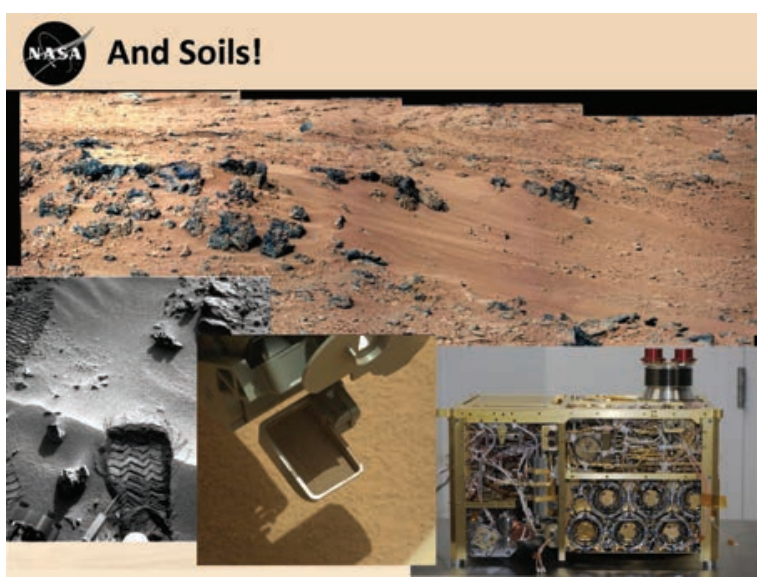

We've been investigating rocks with the arm, but then we really wanted to get into our analytical instruments. And the first sample we used for that was a soil. The dirt on Mars like in this dirt right here at a place we called Rocknest because it looks like a nest of rocks, right? Really creative. The soil on Mars we've analyzed it previously with an APXS instrument at a lot of different sites because an APXS flew on Pathfinder and there's one on each of Spirit and Opportunity. Based on results from all these rovers, including Curiosity, it looks like this soil is pretty much the same everywhere on Mars. That's what makes it a good first sample because it teaches us about the global layer or Mars dirt. So we found this nice sandy spot and we scuffed it with our wheel to make sure that it didn't have a bunch of rocks in it. And then we scooped up some sample here in our scoop and we sieved it to grain sizes only 
less than 150 microns or about a width and a half a human hair. And then we stuck it into those instruments in the belly of the rover.

There are two analytical instruments in the belly of the rover. I'm about show you data from both. One is an X-ray diffraction instrument which tells us the kinds of minerals that make up a material which is very important, and the other is a chemical analysis laboratory. And this is it here, it's called SAM, Sample Analysis at Mars. It's about the size of a microwave oven. And it's a fairly amazing instrument. I will say when I got my PhD at Caltech, I spent 4 years of my life in a windowless lab under the stairs where the ceiling was literally sloped because it was under the stairs, heating up meteorites and extracting water and carbon dioxide from them and then running down the hall to a mass spectrometer and analyzing the composition of those volatiles. And for years and years and years I did that. Well, that's basically all done now inside this instrument on the surface of Mars.

So we take a scoop of material like this and we have a little bit of it that goes in through this sample tube. It's about half the size of a baby aspirin-worth of material. So very tiny amount, $50 \mathrm{mg}$ or so of material. It goes in to a cup which gets put in an oven and then heated up to about 850 degrees centigrade. And the volatiles are released as the volatiles and or volatile bearing minerals break down at different temperatures and that material is carried into three different analytical instruments, all inside this one box. One is a quadrupole mass spectrometer and l'll show you some data from that in a second. That's looking at all masses all the time to look for water and carbon dioxide and can detect organic materials up to a very high mass. And then the next is a gas chromatograph. So these are 6 columns here of our gas chromatograph which is a very sensitive way to detect organic materials and separate them from one another as they go through these different columns. And then the third is a tunable laser spectrometer that allows us to measure isotope compositions that is the amount of different types of carbon 13 versus carbon 12, deuterium versus hydrogen in water and carbon dioxide which is kind of my thing. I am an isotope geochemist and it's exciting that we are able to make isotope measurements here with the tunable laser spectrometer inside of SAM.

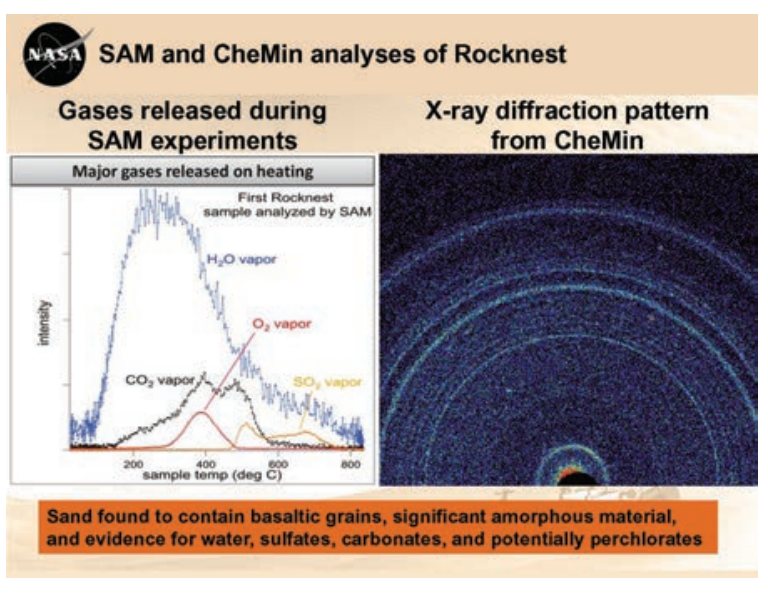

We heated up this very first soil and as we analyzed it in our $X$-ray diffraction instruments, and here's what we saw. This is our first geochemical laboratory results on Mars with Curiosity. So first of all, on the right our X-ray diffraction pattern from different minerals in the soil and it's interesting we found it mostly looks like it's physically broken up volcanic rocks. Minerals from a basalt like olivine, pyroxene and feldspar that are abundant. But interestingly it also contains a significant amount of material that was not crystalline, it was amorphous. It didn't have long range order. Maybe $30 \%$ or one-third of the fine grained material on Mars is this amorphous material, which is a surprise, and it's very interesting.
And then we can look on the left at what we got from SAM from heating up that material. Here's the temperature of the sample going up to 800 degrees versus the intensity for different masses, looking at the quadripole mass spec data now. So this is for example mass 18 looking at water. This is a large amount of water that's released at maybe 300 degrees C. Carbon dioxide a couple of peaks here of $\mathrm{CO}_{2}$ release, a big oxygen release which is very interesting and consistent with results that Viking had previously seen, and also sulfur dioxide. And we also saw some minor phases as well. But that water - to me this is one of the most interesting results.

There's maybe two to three weight percent water in this soil. It's quite water rich. Even though most of the minerals are actually not water bearing, they're mostly anhydrous minerals that we see with the X-ray diffraction instrument, so that means that most of the water's probably in the amorphous material. So if I'm an astronaut that's going to Mars and I want to try to live off the land, it's very good - all you have to do is scoop up some dirt and heat it up and you can get plenty of water out. And of course if you're going to try to - if you're a living thing trying to live in the soil that's also good to have there. So it's very interesting. So we've got our first papers that have been submitted for publication that aren't yet out that will give more details on all of this but hopefully they'll be out in the next couple of months. So that was the dirt. 


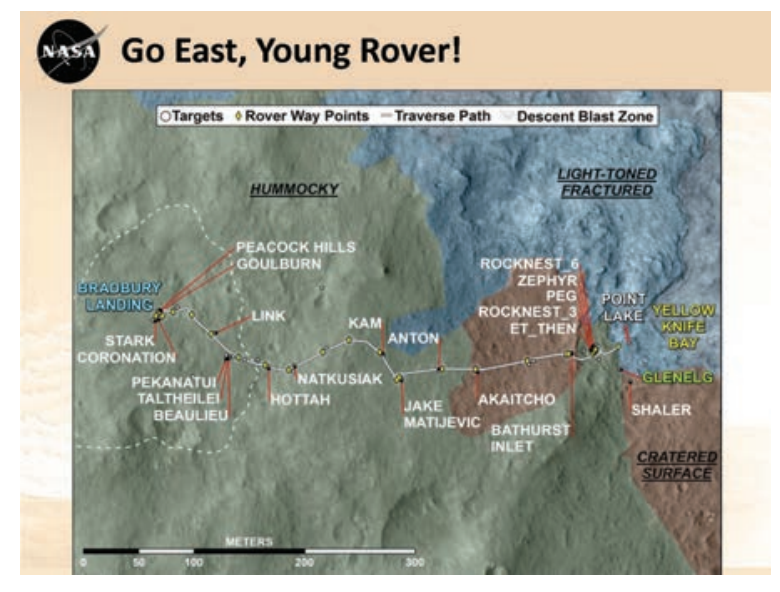

Moving on from looking at the dirt on Mars, let me tell you a little bit about where we're sitting today. This is a little bit complicated but don't worry about it. This is where we landed, right over here. And we've driven only about 500 or $600 \mathrm{~m}$ to the east from where we landed. We're currently sitting right over in here, in this little place called Yellowknife Bay. And it's interesting when we landed actually the mountain itself is kind of this way so we sort of are driving in the opposite direction right now, don't tell anyone, but we'll get back to the mountain here in a minute, but we saw when we landed that we landed right next to this very interesting looking feature here at the intersection of three different geologic units. So that's what the colors are on this map. Sort of this hummocky terrain, this more cratered surface and then there's this very light toned fractured unit here. And also this little region here, Yellowknife Bay is, remember I told you in the white part of the crater the lowest region? This is kind of the lowest of the low in that low region on the floor of the crater. So if we're going to be looking for evidence of water, this is a great place to go. So we said you know what? We're so close, we are only 500 $m$ away from there, let's drive over there and try to do our first drilling campaign.

So this is Rocknest where we did our first scoop and now we're sitting down here on the floor of this crater. And as we were driving down into there, we found some other interesting rocks right down here. I'm just going to show you these because they're really cool.

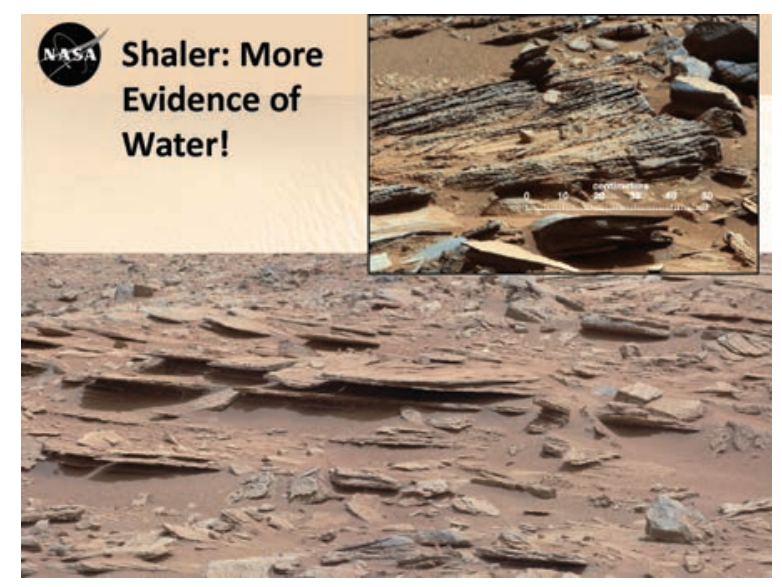

This is a place we called Shaler, nice thinly bedded layers here and if you look really closely here you can see some, for the geologists, some nice cross bedding here. And we think again that this look like they were laid down in the presence of water. They've also got some very nice concretions in them that seem to be getting chemical evidence of mobilizing elements.

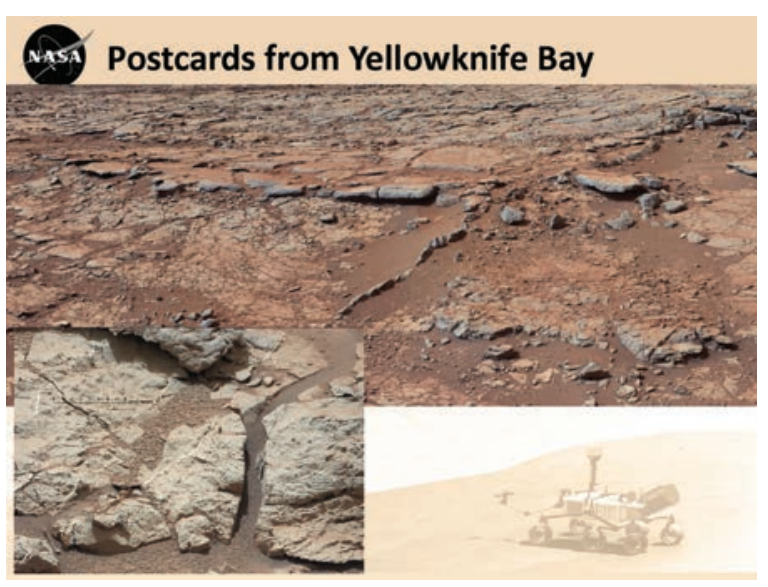

And then we drove down onto the floor of Yellowknife Bay. Now I have to say that as we're getting closer to Yellowknife Bay, people started doubting that it was going to be interesting. As we were driving up to it we thought, oh gosh this looks kind of like volcanic rocks. It doesn't necessarily look like rocks that were laid down by water, but as soon as we got down there on to the floor of Yellowknife Bay, we started seeing and I hope you can see this. You see that white fracture right there. So these rocks are shot through with white veins. It looks like water has flowed like crazy through these rocks. And also they are full of things like these fractures and cracks. 

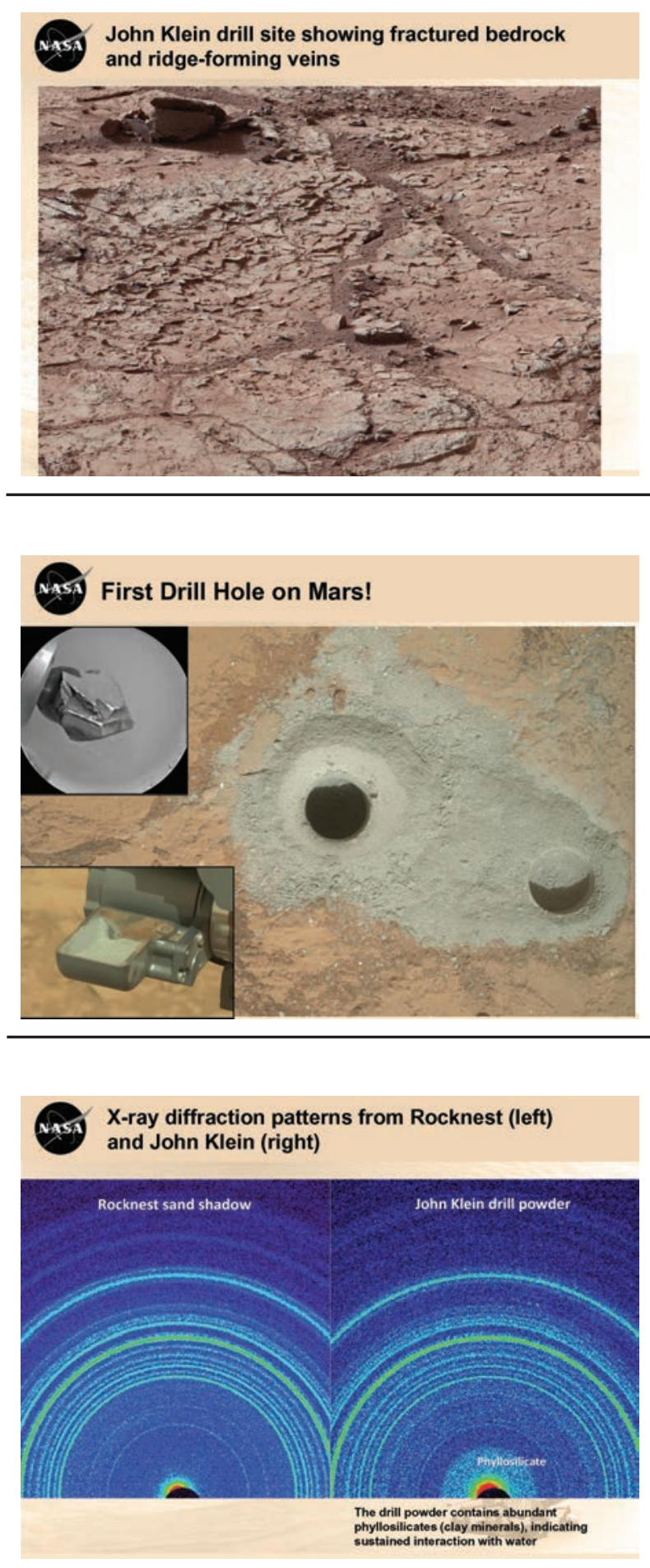

These always look like dried up mud to me. And so this is where we decided we would do our very first drilling. We have a drill on the end of the arm that can drill into rocks and sample them. And this looks like a great place to do that.

So we did our first drill hole. This is the first ever drill hole on Mars. The bit is only about a centimeter across. So always looks bigger on the pictures but it's really quite a small and the hole is only maybe $5 \mathrm{~cm}$ deep. The interesting thing here is the surface of Mars is red. Mars is red for a reason. It's very oxidized at the surface. As soon as we drilled down into this rock, it was nice and gray which if you're trying to preserve organic material, this is very important. We think that in the soil if there was organic material that it's probably mostly been oxidized away. Here we are more hopeful that we'll find organics preserved in the rocks that we can drill. So that was our first hole.

This is a comparison of the scooped Rocknest dirt that I showed you previously with the drill powder from the first samples, we call this drill hole we call John Klein, it's named after one of the engineers on Curiosity who passed away recently. They look pretty similar overall and they are pretty similar. You can see the same features, but down here you can see there's a difference, all right? And this is minerals that are like clay minerals called phyllosilicates that seem to be preserved, that seem to be different in the rock than they are in the soils. 

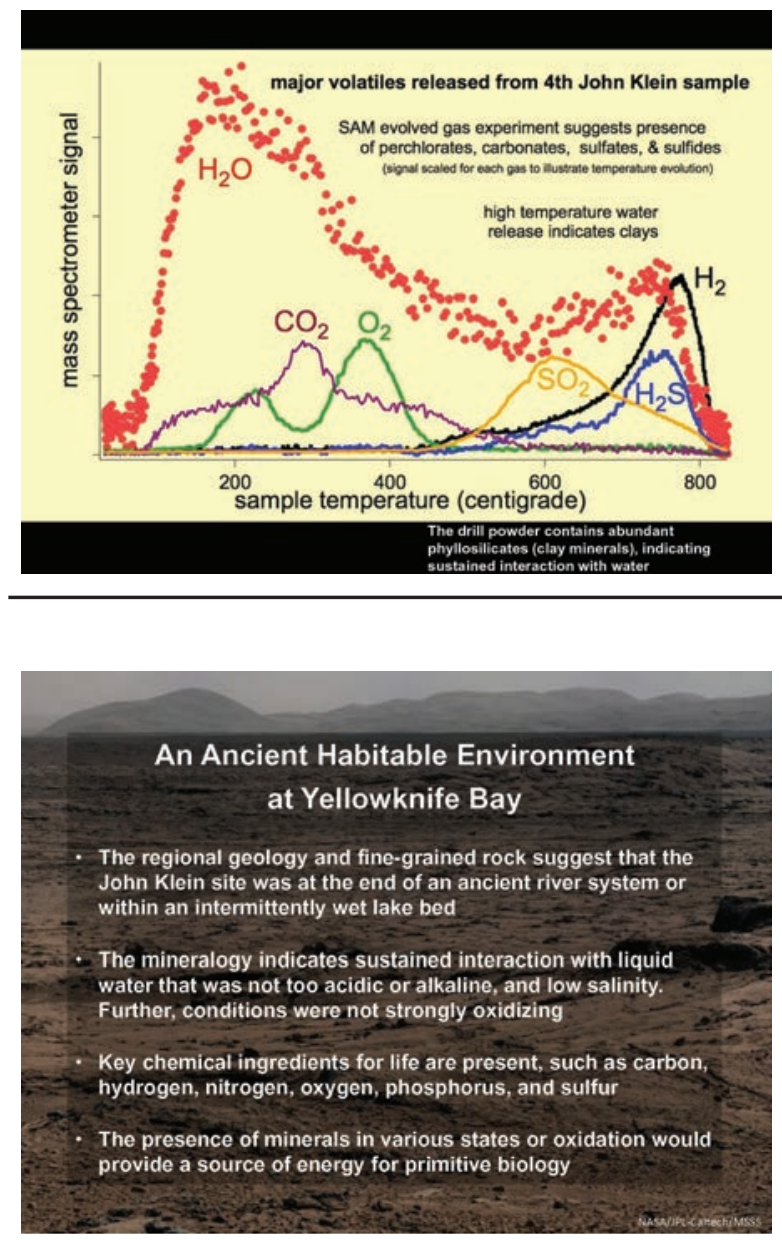

I've taken the summary slide of the environment at Yellowknife Bay directly from our mission scientist so that I can make sure you see kind of the conclusions of the team here. But you know we went to Mars to look for habitable environment and within 6 months we found one - it's very exciting.

The original geology that we've seen here and the fine grain rocks that we find at the John Klein drill site looks like they are the distal end of an ancient river system. Remember those dried up riverbeds that suggest that water formerly flowed into this crater? We look like we're sitting at the end of an alluvial fan system that was deposited at the end of that. And it was probably an intermittent wet lake
And we see that also when we heat up the samples in SAM, we've seen not just this low temperature water peak which is still there and this carbon dioxide and such, but a higher temperature water peak as well which again is indicative of clay materials that are indigenous to this rock. So here we have a nice fine grained soft rock, probably produced in relatively reducing aqueous environment that seems to have been a very nice place to live, if you were a microbe on Mars. bed. We see from the kinds of minerals we have with those clay minerals that there was sustained interaction with liquid water, it looks like unlike other places on Mars where we found evidence of water with say the Opportunity Rover that looked like they were very acidic, this actually looks like it was a fairly benign environment chemically. So not only was it aqueous but it wasn't very, very acidic or very, very saline, it just looks like a perfectly happy place to live if you are a microbe on Mars three and a half billion years ago. And it does have the key ingredients necessary for life carbon, hydrogen, all these various chemicals that we can detect with the rover. So all the raw materials are there. And it's got possible energy sources - we seem to see interesting sulfur chemistry - they were both oxidized and reduced forms of different minerals in coexistence which could provide great "food" if you will, for a microbe living in this environment.

So, all this seems to say that it's a nice place to live but did anybody live there? That's the question. Were there any simple life forms in this lake bed and the answer is we don't know yet. Stay tuned. We're still working on extracting the best data for whether or not any organic materials were present and how those might compare to what we might expect for living systems. It's too soon to tell. That we would be lucky enough on the first place that we drilled to find evidence of life would be too much to ask! But we're definitely still working on it. So stay tuned on more information there. 


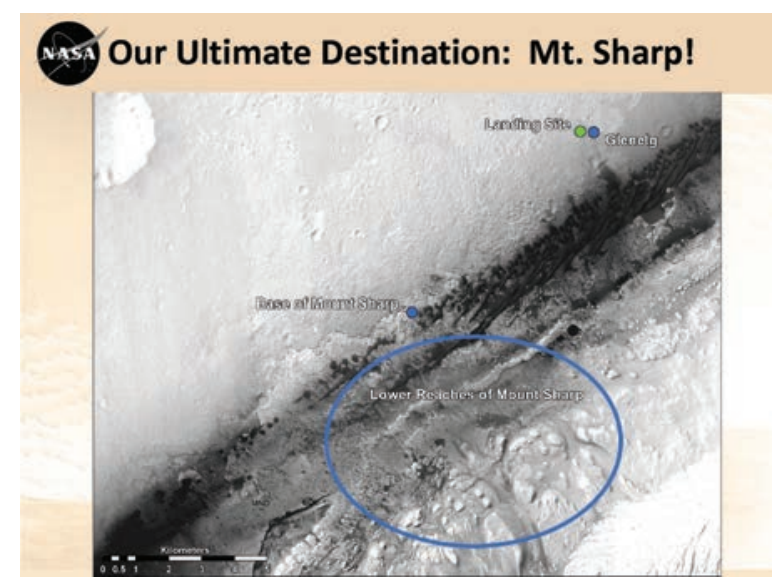

We're finishing up here right now. By the middle of June we will be done in Yellowknife Bay and we will be ready to head for the mountain. So just to again get you oriented, these are the dark dunes, the mountain is down here, here's where we landed, here's where we're sitting now. You can see that we haven't gone very far at all from where we landed. The odometer on Curiosity says $600 \mathrm{~m}$. We need to put some serious mileage on this thing. So we're going to start a very long drive to where we think is a good entry point for Mount Sharp. We don't really want to drive across these dunes. We lost spirit because she got stuck in dunes. So we're going to try to avoid that. And there's a nice little canyon to drive up right here. So we're going to set out for there in about the middle of June. It's probably going to take 4 or 5 maybe even 6 months for us to get there. The rover only drives 50 to $100 \mathrm{~m}$ a day. It's not a speed racer on Mars. And then we'll start heading up the mountain.

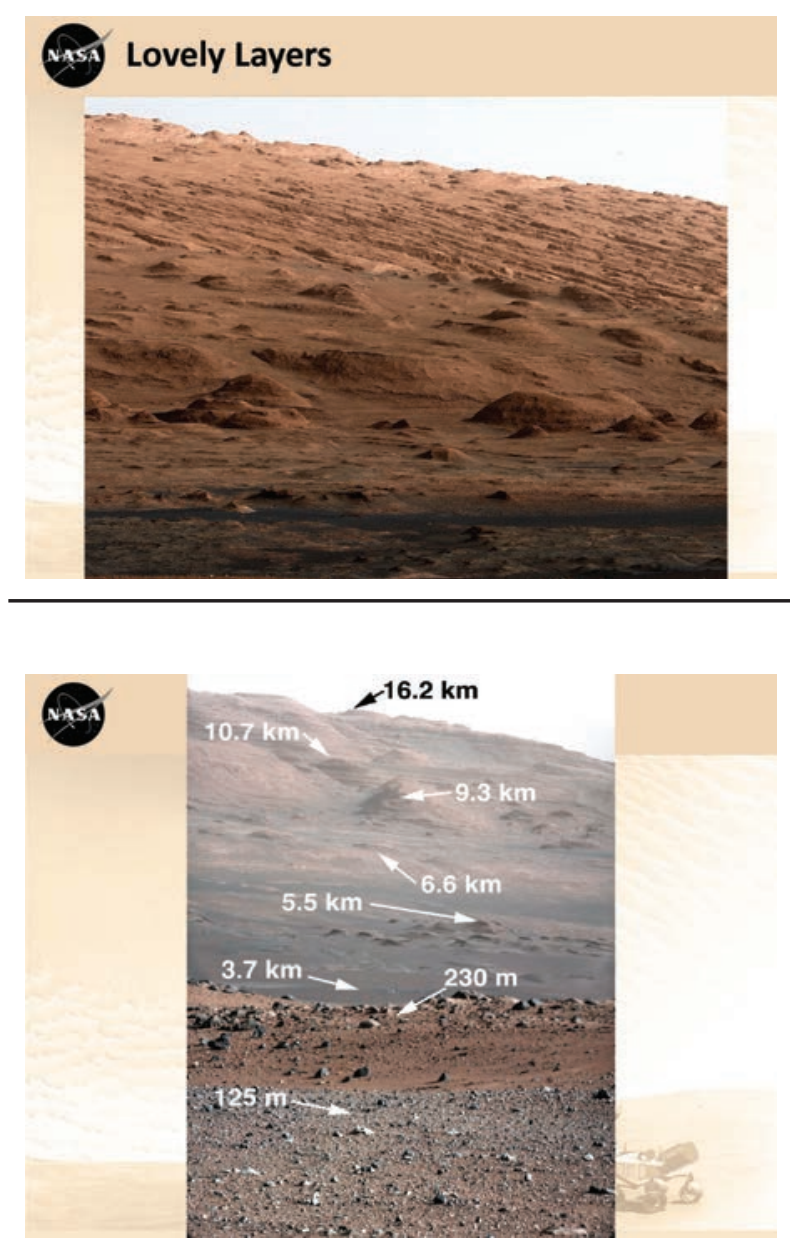

And we've got some views already that tell us that mountain is going to be a spectacular place to explore. We've taken images from where we sit now. These are beautiful pictures of the mountain. There are those dark dunes and you can start to see here some of these gorgeous layers that we saw from orbit and even some interesting things up higher.

Just to give you a sense of scale here, from where we're sitting to where we want to go, you can see it's 6 to $10 \mathrm{~km}$ away so it's going to take us some time to get there. Here again my favorite image of the mountain so far. 

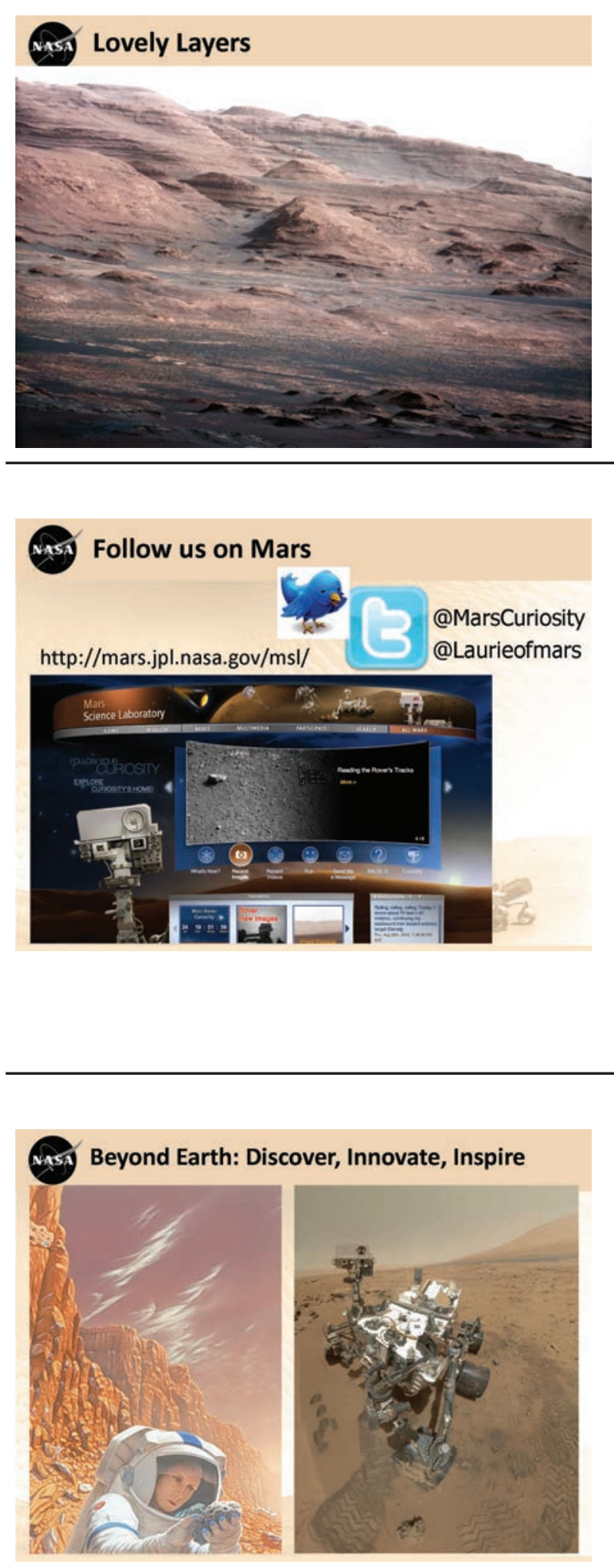

So look at these, look at the textures here, you can see the different layers have different textures to them. So there's clearly going to be some variation in the rocks that we see as we drive up. We are very excited to get in there and start drilling into those rocks and start analyzing them. That's what's coming next, starting later this year with Curiosity.
As I finish up l'll just say that you can follow us on Mars. This is a mission in the era of social media. It's actually quite fascinating. We get down images every single day. Every one of those images goes immediately to the website. So if you go to our Curiosity website and go to multimedia, there's a raw images button where literally every single day you can get the pictures and the way that the rover works as it takes pictures that are kind of postage stamp sizes and then we stitch them together to form large mosaics. It turns out members of the public do this faster than we can. In the era of social media it's fabulous, I love it. And the rover of course being a modern rover, she tweets. She tweets as herself. It's actually three wonderful women at JPL who do it, but it's a great way to follow the mission. And this is me, I'm on Twitter too (@LaurieofMars) and you can follow me and I tweet a lot about the mission.

I'll end by saying that I think there are many possible environments out there where life could have gotten started. By exploring those environments, we are really expanding the reach of humanity either with our robotic partners here and this is Curiosity's selfie. She took the picture of herself with the camera on the end of her arm like you would take a picture of yourself with your cell phone. In this case it's 55 pictures stitched together but we won't go into that. And with mountain in the background and this was actually where we were doing our scooping so that you can see the little scoop marks she made here in the soil. There's a new one of these out now from our drill site as well that you can find on our website. She is as a robotic explorer but the work that she's doing is going to pave the way for the human explorers as well. She's found a radiation environment that's not much worse than the radiation environment on the space station. 
So if we think about sending humans to Mars, she's going to help pave the way for that and it may well be that it takes human explorers to really answer these questions about whether or not life got started on Mars. I think the goal of getting humans there safely to really do that scientific exploration is a laudable one and it's something that we can do if we all work together. So that when that first astronaut takes a step on Mars, I think she may be have a Molecular Frontiers Foundation T-shirt on underneath her outfit there because it's going to be somebody who understands chemistry and biochemistry will be a very helpful astronaut there and you tell she's a girl because she's got blue nail polish on. I think there's a bright future ahead for astrobiological exploration of planets Thank you so much.

\section{Epilogue}

Key publications that resulted from the data shared in this talk include:

Bish, D.L., Blake, D.F., Vaniman, D.T. et al. X-ray diffraction results from Mars science laboratory: Mineralogy of Rocknest at Gale Crater. Science 341(6153), 1238932 (2013).

Blake, D.F., Morris, R.V., Kocurek, G. et al. Curiosity at Gale Crater, Mars: Characterization and analysis of the Rocknest Sand Shadow. Science 341(6153), 1239505-1239505 (2013).

Grotzinger, J.P., Sumner, D.Y., Kah, L.C. et al. A Habitable Fluvio-Lacustrine Environment at Yellowknife Bay, Gale Crater, Mars. Science 343(6169), 1242777 (2014).
Leshin, L.A., Mahaffy, P.R., Webster, C.R. et al. Volatile, Isotope, and Organic Analysis of Martian Fines with the Mars Curiosity Rover. Science 341(6153), 1238937-1238937 (2013).

Ming, D.W., Archer Jr., P.D., Glavin, D.P. et al. Volatile and Organic Compositions of Sedimentary Rocks in Yellowknife Bay, Gale Crater, Mars. Science 343(6169), 1 (2014).

Stolper, E.M., Baker, M.B., Newcombe, M.E. et al. The Petrochemistry of Jake_M: A Martian Mugearite. Science 341(6153), 1239463-1239463 (2013).

Vaniman, D.T., Bish, D.L., Ming, D.W. et al. Mineralogy of a Mudstone at Yellowknife Bay, Gale Crater, Mars. Science 343(6169), 1 (2014). 